\title{
Fractional order PID controller tuned by bat algorithm for robot trajectory control
}

\author{
Mohammad A. Faraj, Abdulsalam Mohammed Abbood \\ Department of Electrical Engineering, College of Engineering, University of Anbar, Ramadi, Iraq
}

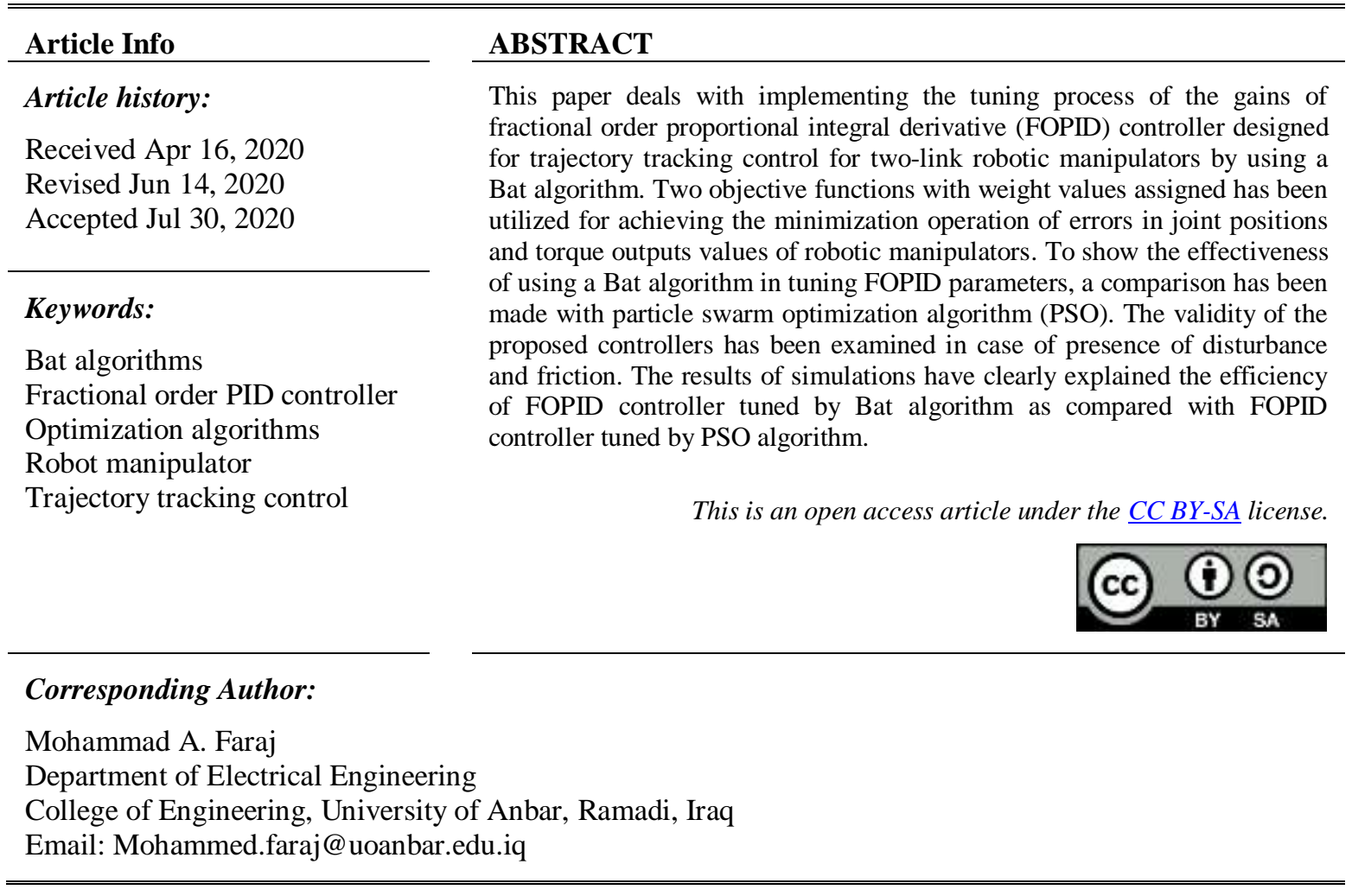

\section{INTRODUCTION}

Robot manipulator has been recently employed in several industrial applications. The existing of Robot manipulators in these industrial applications has been made the designers to make a lot of efforts for solving the problems of controllers' design associated with robot work [1-2]. The complexity in manipulator structure has been made the trajectory tracking control of robotic manipulators is a challenge problem [3]. For treating these problems, many methods have been introduced including computed torque method [4], optimal control [5], variable structure control (VSC) [6], model based adaptive FOPID [7]. The main disadvantages of these types of controllers is the needing of deriving complicated mathematical model for the manipulator. The limitations obtained from these methods has been brought bad results and unstable systems. To overcome these limitations, authors present an intelligent control technique which do not need the knowledge of the mathematical model of the manipulator, such as neural network fuzzy logic, wavelet network [8-10]. On the other hand, the various limitations of traditional PID controllers, such as error calculating, noise in the derivative control; simplification, has been made the designers to improve the performance of classical PID controllers depending on some concepts with mathematics background of fractional calculus that deals with integrals and derivatives using non-integer orders. FOPID controllers has been created and named by Podlubny [11]. The performance of FOPID controllers had been tested and implemented in numerous applications such as system identification [12], robotic manipulators [13], thermal systems [14], Induction motors [15], and power systems [16]. The using of FOPID controller enables the designers more degree of freedom for the selection of controller parameters. According to designee criteria, five parameters $(\mathrm{kp}, \mathrm{kd}, \mu, \mathrm{ki}$ and $\lambda$ ) need to be tuned. The tuning of these parameters has recently become 
possible due to developments of an evolutionary optimization algorithms. Several bio inspired optimization techniques has been tested and implemented as powerful tool for solving an optimization problem for different applications such as : genetic algorithm GA [17], particle swarm optimization PSO [18, 19], ant colony optimization (ACO) [20], differential evolution (DE), artificial bee colony [21], Cuckoo search algorithms (CSA) [22, 23], bat algorithm [24]. Many of these algorithms has been focused on tuning FOPID controller parameters for robotic manipulators [17, 18, 22, 23, 25]. One of these efficient optimization algorithms that is used in tuning FOPID controller parameters is a Bat algorithm. Bat Algorithm has been used as powerful tool in optimization operation for many applications [26-30]. Bat algorithms has become popular among researchers, some of these features is concerned with number of parameter used for initializations where a lower number of parameter used as compared with other types of swarm based algorithms. The other important feature is that bat convergences rate is independent of its parameters $[24,29,30]$. This paper can be constructed as follow: after a brief introduction in Section 1, the deriving of the mathematical model of robot manipulator has been explained in Section 2. In Section 3, the description of FOPID controller structure will be drawn. In Section 4, an explanation of PSO and Bat algorithms are involved. The simulation results have been explained and discussed in detail in Section 5. Finally, the conclusions of the present work and suggestions notes for future works has been drawn in Section 6.

\section{DYNAMIC MODEL OF ROBOTIC MANIPULATOR}

For controller design, it is necessary to have a mathematical model of system. The dynamic equations of an $\mathrm{n}$-link robot manipulator can be derived depending on the Lagrangian formulation as [3]:

$$
M(q) \ddot{q}+C(q, \dot{q}) \dot{q}+G(q)+F(q, \dot{q})+\tau_{d}=\tau
$$

Where $M(q) \in R^{n \times n}$ is a symmetric and positive definite inertia matrix, $C(q, \dot{q}) \dot{q}$, the Coriolis/centripetal vector, and $\mathrm{G}(\mathrm{q})$ is the gravity vector, $F(q, \dot{q})$ the friction vector contains viscous and coulomb friction, and $\tau_{d}$ is a bounded unknown disturbance (including unstructured unmolded dynamics ). A two-link robot manipulator can be can be described as in (2):

$$
\begin{aligned}
& {\left[\begin{array}{ll}
M_{11} & M_{12} \\
M_{21} & M_{22}
\end{array}\right] \ddot{q}+\left[\begin{array}{ll}
C_{11} & C_{12} \\
C_{21} & C_{22}
\end{array}\right] \dot{q}+\left[\begin{array}{l}
G 1 \\
G 2
\end{array}\right]+\left[\begin{array}{l}
D_{i s t 1} \\
D_{i s t 1}
\end{array}\right]=\left[\begin{array}{l}
\tau_{1} \\
\tau_{2}
\end{array}\right]} \\
& \text { Where: } M_{11}=\left(m_{1}+m_{2}\right) l_{1}^{2}+m_{2} l_{2}^{2}+2 m_{2} l_{1} l_{2} \cos \left(q_{2}\right), M_{12}=M_{21}=m_{2} l_{2}^{2}+m_{2} l_{1} l_{2} \cos \left(q_{2}\right) \text {, } \\
& M_{22}=m_{2} l_{2}^{2} C_{11}=-m_{2} m_{2} l_{1} l_{2} \sin \left(q_{2}\right) \dot{q}_{2}, C_{12}=-m_{2} m_{2} l_{1} l_{2} \sin \left(q_{2}\right) \dot{q}_{1}-m_{2} m_{2} l_{1} l_{2} \sin \left(q_{2}\right) \dot{q}_{2}, \\
& C_{21}=m_{2} m_{2} l_{1} l_{2} \sin \left(q_{2}\right) \dot{q}_{1}, G_{1}=g\left(\left(m_{1}+m_{2}\right) l_{1} \cos \left(q_{1}\right)+m_{2} l_{2} \cos \left(q_{1}+q_{2}\right)\right) G_{2}=g m_{2} l_{2} \cos \left(q_{1}+q_{2}\right) \text {. } m_{1} \text { and } \\
& m_{2} \text { are masses and } l_{1} l_{2} \text { are lengths of link } 1 \text { and } 2 \text {, respectively. } \tau_{1} \text { and } \tau_{2} \text { are torque at joints } 1 \text { and } 2 \\
& \text { respectively. }{ }^{d}(t) \text { is unknown but bounded external disturbance with: }\left|d_{i}(t) \leq d_{u i}\right|, i=1,2 \text {. }
\end{aligned}
$$

\section{FRACTIONAL ORDER PID CONTROLLER STRUCTURE}

When an integrator of order $\lambda$ and a differentiator of order $\mu$ is added to classical PID controller with real numbers. The transfer function of a controller has the structure shown in (3):

$$
U(s)=\left(K_{p}+K_{I} \frac{1}{s^{\lambda}}+K_{D} s^{\mu}\right) E(s)
$$

Where, $\mathrm{E}(\mathrm{s})$ is the error, and $\mathrm{U}(\mathrm{s})$ is controller's output. The control signal $\mathrm{u}(\mathrm{t})$ can be defined in the time domain as:

$$
U(t)=\left(K_{P} e(t)+K_{I} \frac{d^{-\lambda}}{d t^{-\lambda}} e(t)+K_{D} \frac{d^{\mu}}{d t^{\mu}} e(t)\right)
$$




\section{FRACTIPONAL ORDERR PID (FOPID) TUNED BY OPTIMAZTION ALGORITHMS}

In this work, the fife parameters of FOPID controller will be tuned using Bat algorithm (BAT). To show the effectiveness of this algorithm over other optimization algorithms, Bat algorithm will be compared with particle swarm optimization algorithm (PSO). The block diagram of closed loop control system involving FOPID controller is shown in Figure 1.

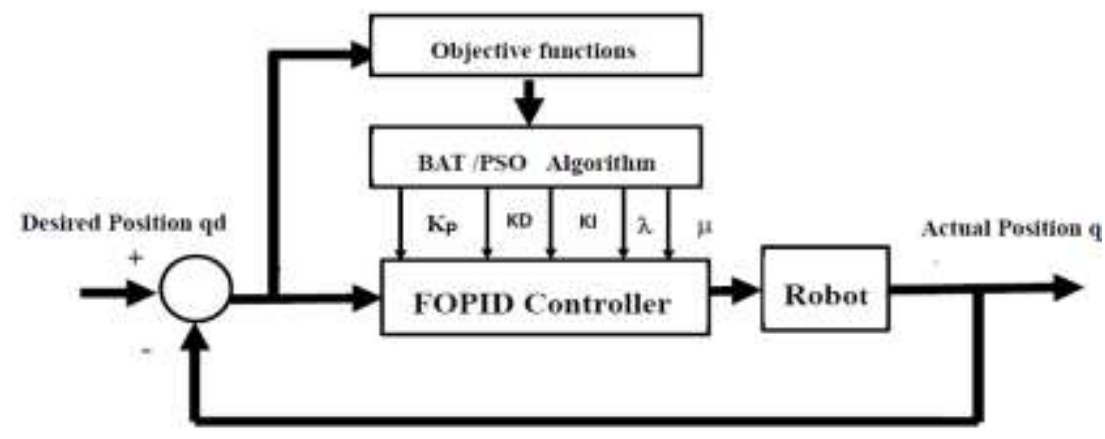

Figure 1. Manipulator position control system using FOPID controller tuned by BAT/PSO algorithms

\subsection{Particle swarm optimization (PSO)}

PSO is an optimization algorithm invented by Kenndy and Eberhart in 1995, inspired from social behavior of animals (birds, fishes, insects) in their swarms when they search to find their foods. PSO has been proven as an effective optimization method for solving optimization problems in many nonlinear systems applications. An initial position and velocity values are assigned in this algorithm. These values moving through the search space and then appreciated according to criteria's of particular objective function [31]. For each iteration, there are two values obtained, the first one is the best local values resulting from particle previous experience for itself and called personal best (Pbest). The second values are coming from having the best position in the swarm and called globel best (gbest). In (5) and (6) describe the velocity and position of updating process for each particle in the swarm:

$$
\begin{aligned}
& v_{i}^{k+1}=w^{*} v_{i}^{k}+c_{1} R_{1} *\left(\text { lbest }_{i}-x_{i}^{k}\right) f_{i}+c_{2} R_{2} *\left(\text { gbest }_{i}-x_{i}^{k}\right) \\
& x_{i}^{k+1}=x_{i}^{k}+v_{i}^{k+1}
\end{aligned}
$$

Where: $x_{i}^{k}$ is position of particle $\mathrm{i}$ at iteration $\mathrm{k} ;{ }^{k}{ }_{i}^{k}$ is the velocity of particle $\mathrm{i}$ at iteration $\mathrm{k} ; \boldsymbol{w}$ is the inertial weight, $\boldsymbol{C}_{1}$ and $\boldsymbol{C}_{2}$ are the acceleration constants; $\boldsymbol{R}_{1}$ and $\boldsymbol{R}_{2}$, are a random variables between 0 and $1[19-21]$.

\subsection{Bat optimization algorithm (BAT)}

In 2010 Xin-She Yang has been developed a population-based metaheuristic optimization technique like PSO and GA. This algorithm simulates the behavior of micro bat animals to take their prey/food by and called it Bat algorithm [24]. The algorithm imitates the echolocation behavior of micro bat by varying its emission pulse rate and loudness. Three general rules developed by Xin-She Yang has been considered as the biases of bat algorithm operations as the following [24]:

a) Sensing distance, distinguishing the difference between food/prey and knowing background barriers are achieved by all bats by using echolocation.

b) When search on particular prey, bats vary its wavelength $\lambda$ and loudness ${ }_{A_{O}}$ flying randomly with velocity $v_{i}$ at position $x_{i}$ with a frequency $f$ min. Wavelength (or frequency) of emitted pulses of bats can be automatically adjusted. Adjusting of the rate of pulse emission $r \in[0,1]$ is also accomplished depending on the proximity of their goal. 
c) In spite of the ability of the loudness to vary in many ways, it is assumed that the variations of loudness can be from a large (positive) ${ }_{A_{O}}$ to a minimum constant value Amin. Because of the relationship between frequency and wavelength the change can be described in this algorithm either in terms of frequency f or wavelength $\lambda$. Velocity $v_{i}$ and a location $x_{i}$ are assigned to each bat at iteration $\mathrm{t}$ for implementing the bat motion in solution space. There exists a current best solution $\mathrm{x}^{*}$ from all the bats in search space. The rules that describe Bat motion can be formulated as shown in (7-9):

$$
\begin{aligned}
& f \min =f \min +(f \max -f \min ) \beta \\
& v_{i}^{t}=v_{i}^{t}-1+\left(x_{i}^{t}-1-x_{*}\right) f_{i} \\
& x_{i}^{t}=x_{i}^{t-1}+v_{i}^{t}
\end{aligned}
$$

Where, $\beta \in[0,1]$ is a random vector drawn from a uniform distribution. At the beginning a frequency which is drawn uniformly from [fmin, fmax] is randomly assigned to each bat therefore, bat algorithm can be considered as an algorithm concerned with using frequency for tuning providing a balanced method between of exploration and exploitation. The loudness and pulse emission rates essentially provide a mechanism for automatic control and auto zooming into the region with effective solutions [21]. During the iterations, the loudness and pulse emission rates must be varied in an effective away such that getting an effective mechanism for controlling the exploration and exploitation. When the prey has been founded by a bat, the loudness will decrease. at the same time the rate of pulse emission increases, therefore we can be select the loudness between Amin and Amax, with assumption that A min goes to zero when a bat has just reach its prey. In this case the bat will stop emitting sounds. According to these assumptions, (10-11) will be considered [29] :

$$
\begin{aligned}
& A_{i}^{t+1}=\alpha A_{i}^{t} \\
& r_{i}^{t+1}=r_{i}^{0}[1-\operatorname{EXP}(\gamma t)]
\end{aligned}
$$

Where $\alpha$ and $\gamma$ are constants. For any $\mathrm{O}\langle\alpha\langle 1$ and $\gamma>0$, we have [27]:

$$
A_{i}^{t} \rightarrow \mathrm{O},=r_{i}^{t} \rightarrow r_{i}^{\mathrm{O}} \text { as } t \rightarrow \infty
$$

The procedure for implementing Bat Algorithm used in this paper can be found in [24, 25].

\subsection{Objective functions}

Reducing the errors in control system is considered as the main goal of solving the control problem. The assigning and choosing the appropriate objective function for control problems enable us to improve the performance of the system. In this work, the integral absolute error (IAE) and integral absolute change in control output (IACCO) represented in (13) and (14) has been chosen as objective functions in order to make an error reduction between desired and actual positions as well as minimizing the changing in control output.

$$
\begin{aligned}
& J_{1}=\int\left|e_{1}(t)\right| d t+\int\left|e_{2}(t)\right| d t \\
& J_{2}=\int\left|\Delta \tau_{1}\right| d t+\int\left|\Delta \tau_{2}\right| d t \\
& J=w_{1} J_{1}+w_{2} J J_{2}
\end{aligned}
$$

where $\mathrm{e} 1(\mathrm{t})$ and $\mathrm{e} 2(\mathrm{t})$ represent the errors in link one and two respectively; $\Delta \tau 1$ and $\Delta \tau 2$ indicate the controller output changing obtained in Link1 and Link2 respectively. $(w 1=0.8)$ and $(w 2=0.6)$ are the weights assigned to $\mathrm{J} 1$ and $\mathrm{J} 2$ respectively. 


\section{SIMULATION AND RESULTS}

\subsection{Trajectory tracking performance of robotic manipulators using BAT- FOPID controller}

The results that obtained from tracking reference position trajectory for robot manipulator has been indicated and discussed in this section. The simulation is done using MATLAB program. Bat and PSO algorithms are used to tune the parameters of FOPID controllers. PSO algorithms used as comparative method for showing the effectiveness of BAT algorithms. The value of dynamical parameters of robot has been chosen as following : $m_{1}=0.8 \mathrm{~kg}, m_{2}=2 \mathrm{~kg}, \ell_{1}=\ell_{2}=1 \mathrm{~m}$. The trajectory chosen: $q_{d 1}(t)=\pi / 4-\pi / 4 \cos \pi t \quad, \quad q_{d 2}(t)=\pi / 4-\pi / 4 \cos \pi 2 / 1.66 t$. The initial conditions are: $q_{d}(\mathrm{O})=\left[\begin{array}{ll}\mathrm{O} & \mathrm{O}\end{array}\right]^{T}, \dot{q}_{d}(\mathrm{O})=[\mathrm{O} \mathrm{O}]^{T}$.

Figure 2 illustrates the values of fitness versus generation in case of using BAT and PSO algorithms in tuning FOPID controllers. Table 1 indicates the parameters values used in initialization of the BAT and PSO algorithms. FOPID gains and IAE values obtained from using BAT and PSO algorithms are presented in Table 2. The graphs of position response, control signals and errors in position are illustrated in Figure 3. It is obvious from the Table 2 and Figure 3 the superiority of FOPID controllers that used BAT algorithm over than of those used PSO algorithm.

Table 1. Parameters of PSO, BAT algorithms

\begin{tabular}{cccc}
\hline & \multicolumn{4}{c}{ PSO Algorithm BAT } \\
\hline parameter & Parameter values & Parameter & Parameter values \\
Population size & 10 & Population size & 10 \\
Generations & 10 & Generations & 10 \\
Acceleration c1 & 2 & $\mathrm{a}=\mathrm{g}$ & 0.9 \\
Acceleration c2 & 2 & $A_{i}{ }^{0}$ & 0.7 \\
Inertia weigh, $w_{\min }$ & 0.9 & $r_{i}{ }^{\circ}$ & 0.8 \\
Inertia weight, $w_{\max }$ & 0.4 & $f_{\max , \min }$ & 0.1 \\
Iterations & 80 & Iterations & \\
\hline
\end{tabular}

Table 2. IAE and controller parameter for PSO-FOPID and BAT-FOPID controllers

\begin{tabular}{cccccc}
\hline Parameter & $1^{\text {st }}$ link & & Parameter & $2^{\text {nd }}$ link & \\
\hline$K_{P}$ & FOPID with PSO & FOPID with BAT & & FOPID with PSO & FOPID with BAT \\
$K_{I}$ & 56.8 & 33.7 & $K_{P}$ & 11.2 & 18.9 \\
$K_{D}$ & 93.2 & 330.1 & $K_{I}$ & 88.7 & 441.6 \\
$\mu$ & 0.956 & 1.35 & $K_{D}$ & 0.876 & 0.78 \\
$\lambda$ & 0.2888 & 0.41 & $\mu$ & 0.3111 & 0.74 \\
IAE & 0.9765 & 0.95555 & $\lambda$ & 0.077 & 0.876 \\
\hline
\end{tabular}

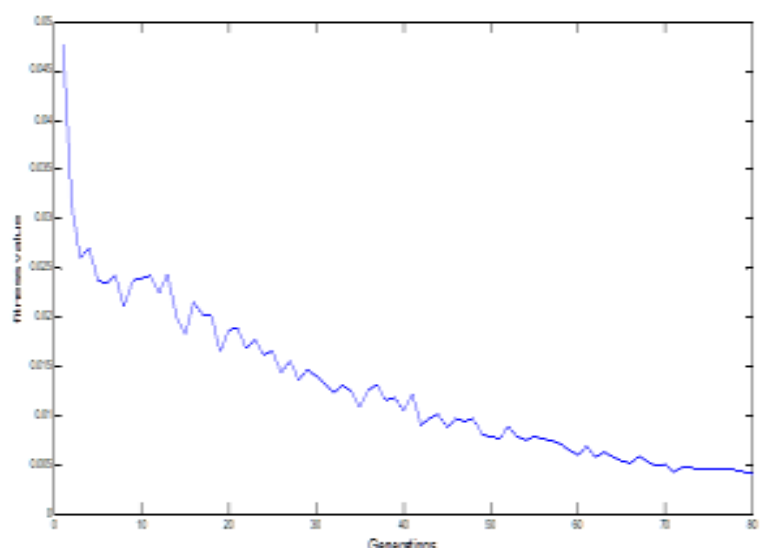

(a)

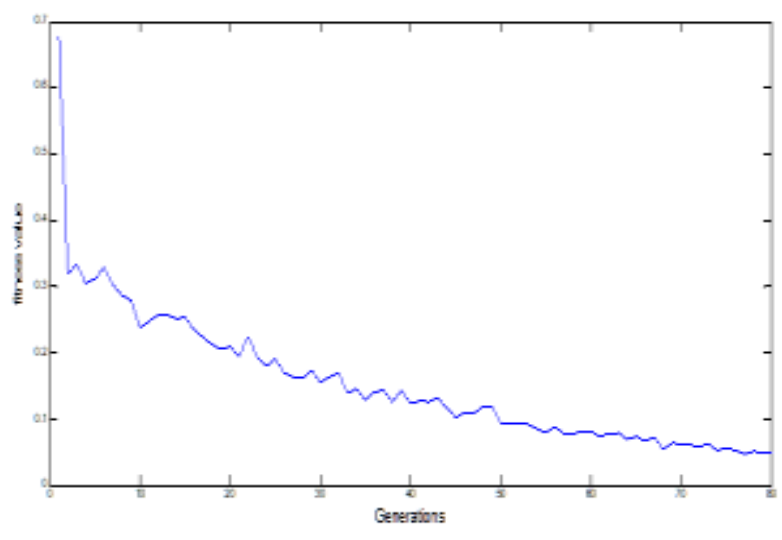

(b)

Figure 2. Fitness value versus generations using (a) BAT, (b) PSO 


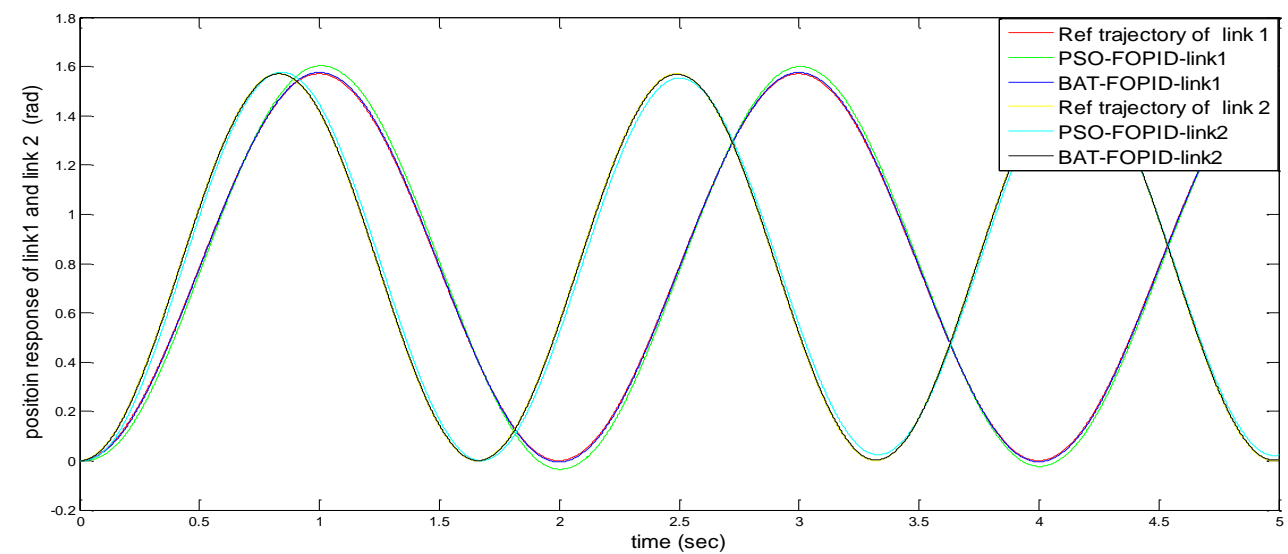

(a)

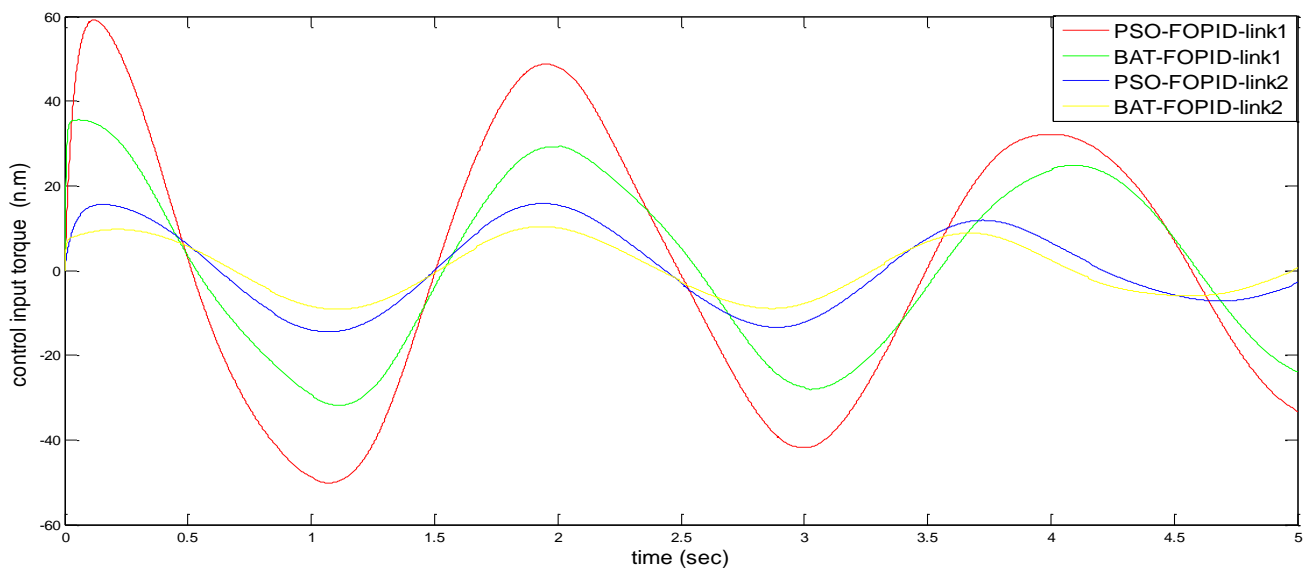

(b)

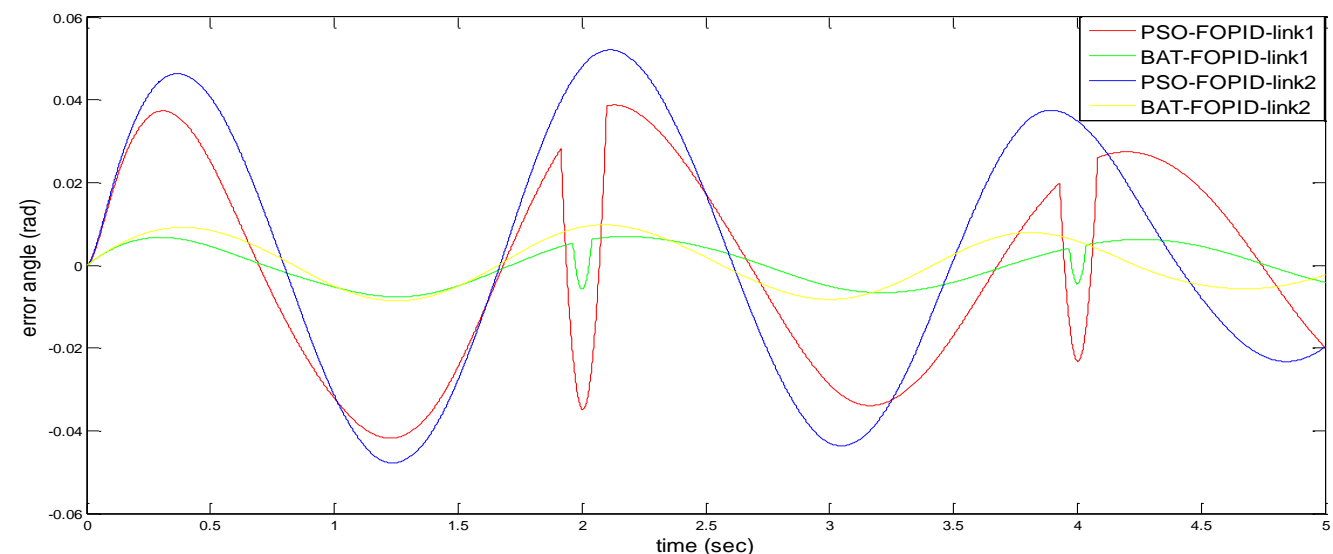

(c)

Figure 3. (a) Position response (b) Control signals (c) Errors in position for robotic manipulator links controlled by FOPID controllers tuned by BAT and PSO algorithms

5.2. Trajectory tracking performance of robotic manipulators using BAT- FOPID controller with sinusoidal disturbances

In this Section, ability of BAT-FOPID and PSO-FOPID controllers to reject the disturbances existence has been investigated. $0.2 \sin (\mathrm{t}) \mathrm{N} . \mathrm{m}$ has been chosen as a disturbance. This disturbance is applied to the controller output of the first Link, second link and both links for the entire 5 sec. Figure 4 illustrates The position response, control signals and position errors graphs when a sinusoidal disturbance is applied. Table 3 indicates an IAE in case of disturbances rejections. It is obvious from the Table 3 that the IAE values for FOPID controllers that used BAT algorithm are lesser than of those used PSO algorithm. 
Table 3. Values of IAE for FOPID controllers tuned by BAT and PSO algorithms in case of rejection of disturbance

\begin{tabular}{ccccc}
\hline \multicolumn{5}{c}{ Disturbance (N.m ) FOPID tuned by BAT Algorithm FOPID tuned by PSO Algorithm } \\
\hline & $1^{\text {st }}$ link & $2^{\text {nd }}$ link & $1^{\text {st }}$ link & $2^{\text {nd }}$ link \\
1st link & 0.0144 & 0.0199 & 0.0415 & 0.0711 \\
2nd link & 0.0180 & 0.0214 & 0.0439 & 0.0827 \\
Both links & 0.0214 & 0.0265 & 0.0612 & 0.0894 \\
\hline
\end{tabular}

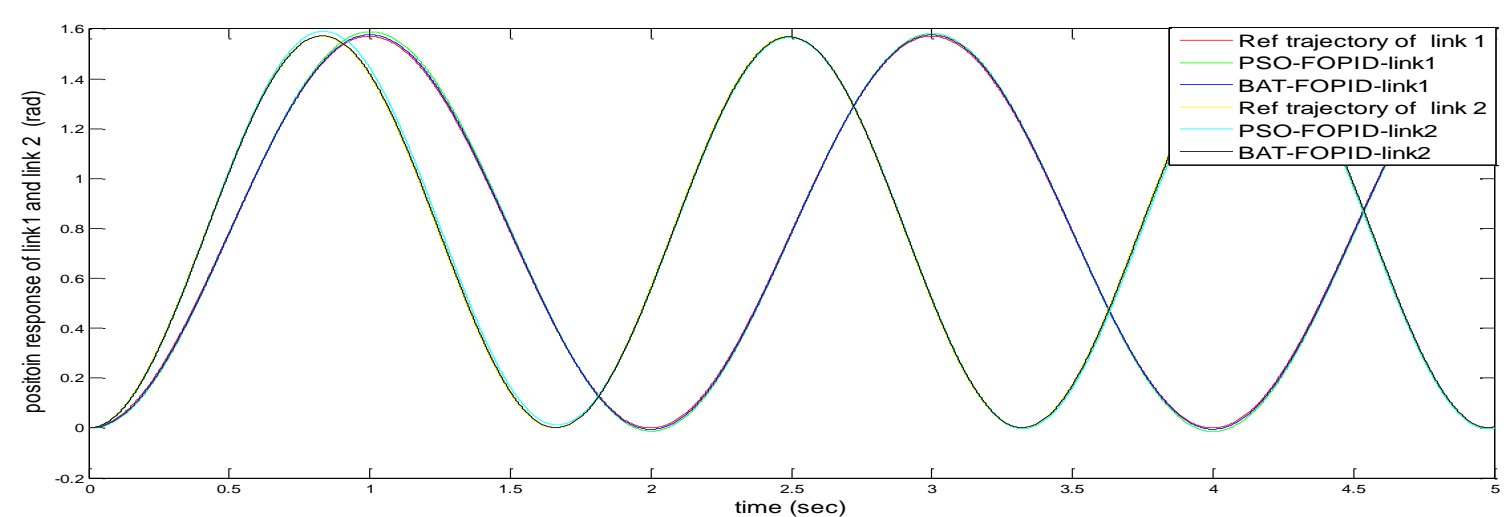

(a)

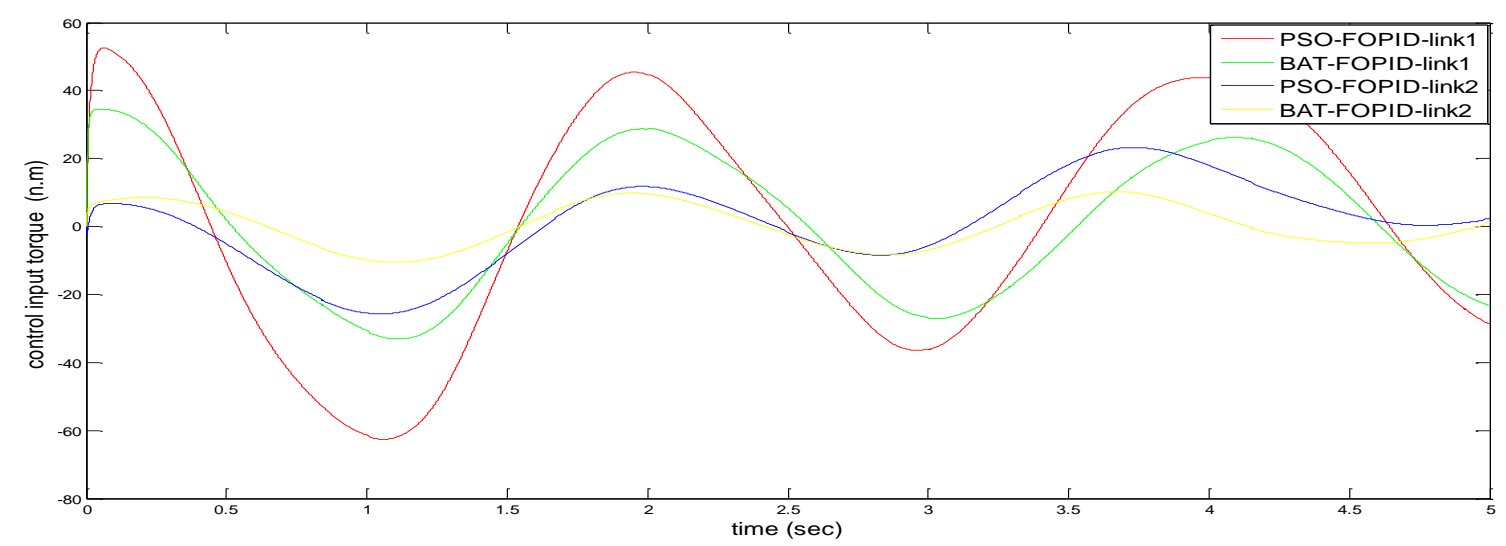

(b)

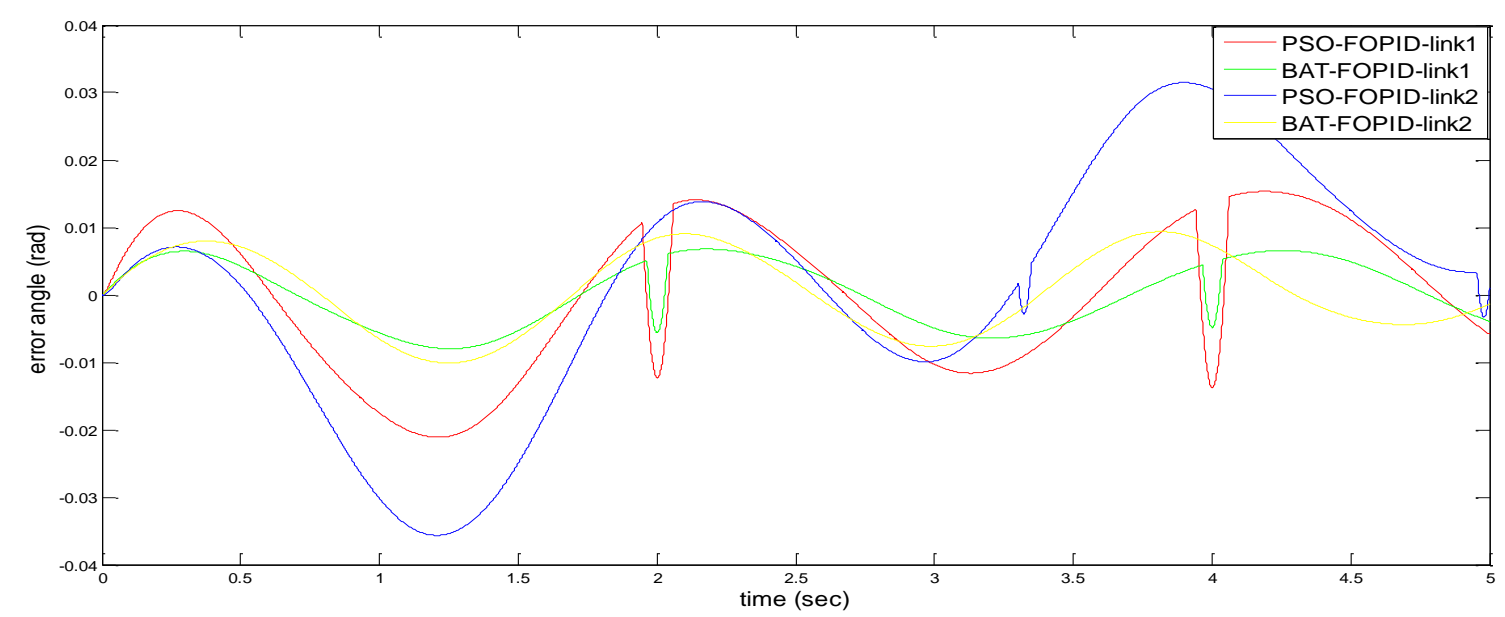

(c)

Figure 4. (a) Position response, (b) Control signals, (c) Errors in position for FOPID controllers tuned by BAT and PSO algorithms in case of Disturbance rejection in link1 and link2 
5.3. Trajectory tracking performance of robotic manipulators using BAT- FOPID controller with friction terms

In this section, friction terms will be applied for two link robotic manipulators. The friction terms $f_{1}\left(\dot{q}_{1}\right)$ and $f_{2}\left(\dot{q}_{2}\right)$ in (1) can be specified using equations: $f_{1}\left(\dot{q}_{1}\right)=c_{1} \operatorname{sgn}\left(\dot{q}_{1}\right)+v_{1} \dot{q}_{1}$. $f_{2}\left(\dot{q}_{1}\right)=c_{2} \operatorname{sgn}\left(\dot{q}_{2}\right)+v_{2} \dot{q}_{2}$, The parameter values are selected as $c_{1}=c_{1}=0.1 \quad v_{1}=v_{2}=2$. The position response, control signals and position errors graphs when a friction terms are applied are illustrated in Figure 5. The IAE values in case of friction terms existence has been indicated in Table 4. It is obvious from the Table 4 that the IAE values for FOPID controllers that used BAT algorithm are lesser than of those used PSO algorithm.

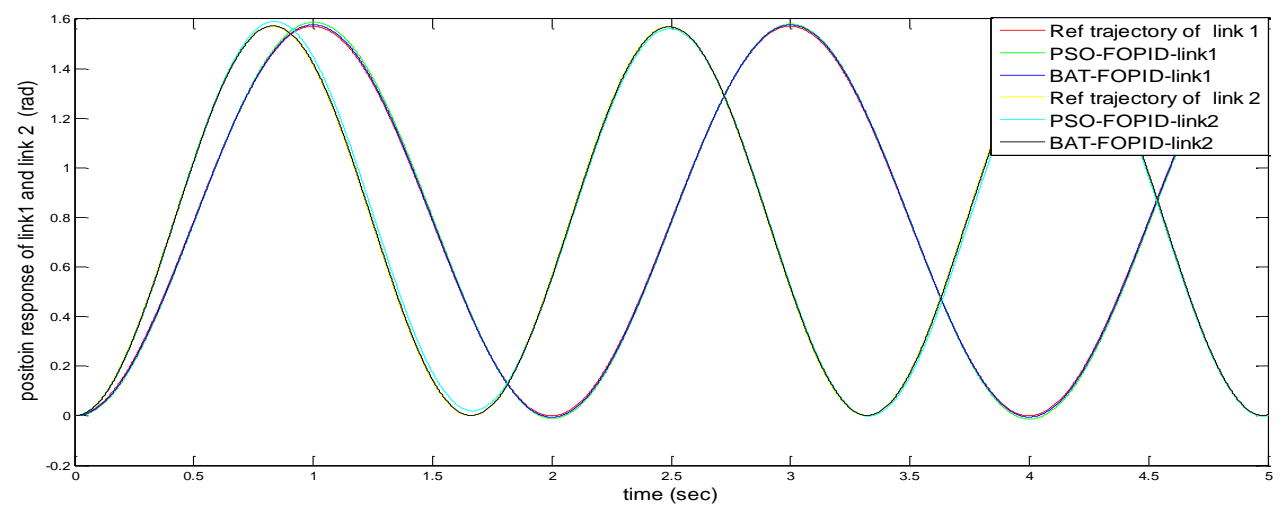

(a)

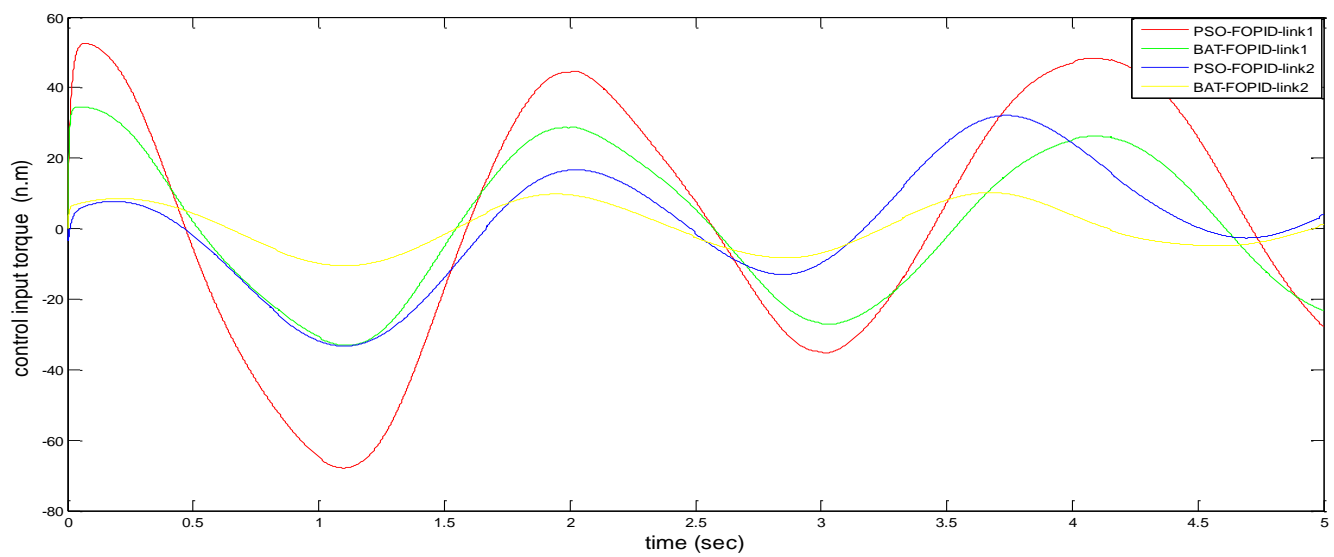

(b)

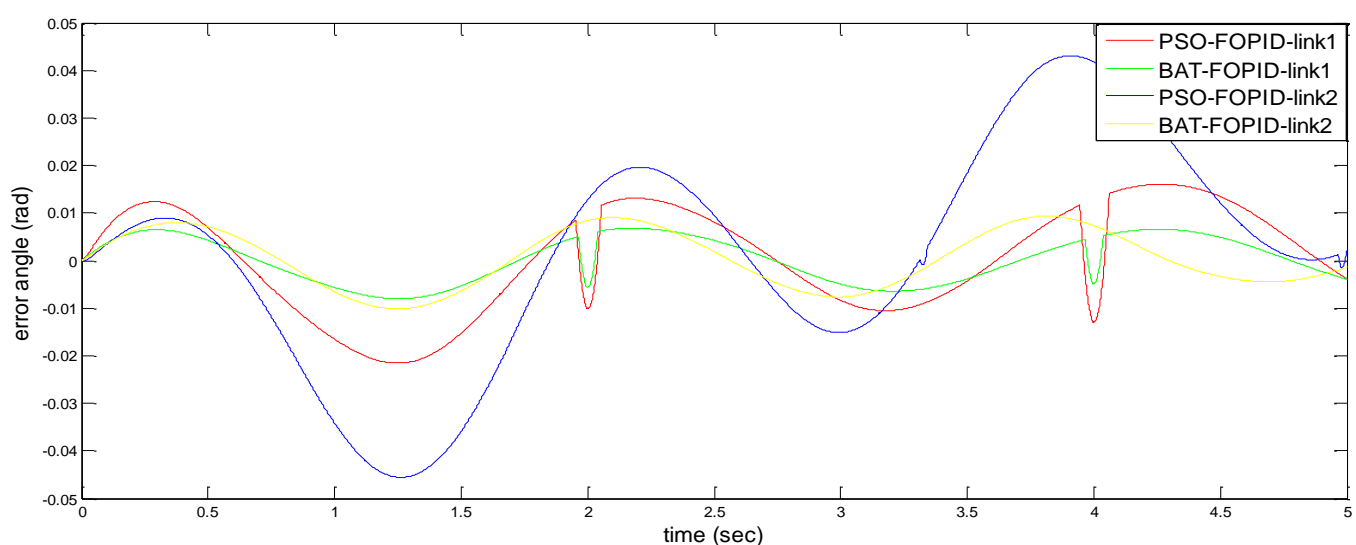

(c)

Figure 5. (a) Position response (b) Control signals (c) Errors in position for FOPID controllers tuned by BAT and PSO algorithms in case of friction existence

Fractional order PID controller tuned by bat algorithm for robot trajectory control (Mohammad A. Faraj) 
Table 4. Values of IAE for FOPID controllers tuned by BAT and PSO algorithms in case of friction existence

\begin{tabular}{|c|c|c|c|c|}
\hline \multirow{2}{*}{\multicolumn{5}{|c|}{ Friction FOPID tuned by BAT Algorithm FOPID tuned by PSO Algorithm }} \\
\hline & & & & \\
\hline Both links & 0.0117 & 0.0199 & 0.0679 & 0.0905 \\
\hline
\end{tabular}

\section{CONCLUSION}

In this work, the FOPID controller tuned by one of evolutionary algorithms called a BAT algorithm are employing for trajectory tracking problem in position control system for a 2-link robot manipulator. FOPID controller tuned by BAT algorithm has been compared with PSO-FOPID controller for position response task. To examine the effectiveness of proposed controllers, the disturbance rejection test and friction terms has been applied to first and second links of robotic manipulators. It can be observed from results of simulation that BAT -FOPID controller is more efficient and accurate when compared with FOPID controller tuned by PSO algorithm in case of position tracking, rejection of disturbance and friction existence. In the future, BAT-FOPID controller can be applied for another types of robotic manipulators.

\section{REFERENCES}

[1] H.Asada, J.E.E. Slotine," Robot Analysis and Control", first ed., Wiley-Interscience, 1986.

[2] J. Schilling, "Fundamentals of Robotics Analysis and Control", first ed., Prentice Hall, 1990.

[3] J. Craig, "Introduction to Robotics: Mechanics and Control", third ed., Prentice Hall, 2005.

[4] F. Alonge, et al.,"Adaptive Control Strategies for Rigid Robots to Reduce Harmonic Content of Driving Torque and Compensate Coulomb Friction", In Proceedings of International Conference on Industrial Electronics, Control and Instrumentation, Taipei, Taiwan, pp. 202-207, Aug 1996.

[5] F. Lin and R.D. Brandt, "An Optimal Control Approach to Robust Control of Robot Manipulators," IEEE Transaction on robotics and automation, vol. 14, no. 1, pp. 69-77, Feb 1998.

[6] F. Piltan, et al., "PUMA-560 Robot Manipulator Position Sliding Mode Control Methods Using Matlap/Simulink and Their Integration into Graduate/Undergraduate Nonlinear Control, Robotics and MATLAB Courses," International Journal of Robotic and Automation, vol. 6, no. 3, pp. 167-191, 2012.

[7] H. Delavari, et al.," Adaptive Fractional PID Controller for Robot Manipulator," The 4th IFAC Workshop Fractional Differentiation and its Applications, Badajoz, Spain, pp. 1-7, Oct 18-20, 2010.

[8] H.Lee, et al., "A Sliding Mode Controller Using Neural Networks for Robot Manipulator", Proceedings On European Symposium on Artificial Neural Networks, Bruges, Belgium, pp. 193-198, Apr 2004.

[9] C-K. Lin, "Adaptive tracking controller design for robotic systems using Gaussian wavelet networks," Control Theory Appl., vol. 149, no. 2, pp. 316-322, 2002.

[10] C-K Lin, "Nonsingular Terminal Sliding Mode Control of Robot Manipulators Using Fuzzy Wavelet Networks," IEEE Transaction on Fuzzy Systems, vol. 14, no. 6, pp.849-859, Dec 2006.

[11] Podlubny," Fractional-order systems and PI $\lambda \mathrm{D} \mu$ controller," IEEE Trans. Automatic Control, vol. 44, no. 1, pp. 208-214, 1999.

[12] Schlegel, M and Cech, M., "Fractal system identification for robust control-the moment approach," in Proceedings of ICCC 2004 Conference. Zakopane, Poland, 2004.

[13] N.M. Fonseca Ferreira and J.A. Tenreiro Machado," Fractional-Order Hybrid Control of Robotic Manipulators," In 11th International Conference on Advanced Robotics, pp. 393-398, 2003.

[14] S. Jesus and J.A.T. Machado," Fractional control of heat diffusion systems," Nonlinear Dynamics, vol. 54, pp. 263-282, 2008.

[15] P. Bhaskara Prasad, M. Padma Lalitha, and B. Sarvesh, "Fractional Order PID Controlled Cascaded Re-boost Seven Level Inverter Fed Induction Motor System with Enhanced Response," International Journal of Power Electronics and Drive System (IJPEDS), vol. 9, no. 4, pp. 1784-1791, Dec 2018.

[16] S. A. Taher, "Fractional Order PID Controller Design for LFC in Electric Power Systems using Imperialist Competitive Algorithm," Ain Shams Eng. J, vol. 5, pp. 121-135, 2014.

[17] Helon Vicente, et al., "Tuning of PID Controller Based on a Multiobjective Genetic Algorithm Applied to a Robotic Manipulator," Expert Systems with Applications, vol. 39, pp. 8968-8974, 2012.

[18] Z. Bingul and O. Karahan, "Fractional PID controllers tuned by evolutionary algorithms for robot trajectory control," Turkish Journal of Electrical Engineering \& Computer Sciences, vol. 20, no. 1, pp. 1123-1136. 2012,

[19] Fadhil A. Hasan and Lina J. Rashad," Fractional-order PID controller for permanent magnet DC motor based on PSO algorithm," International Journal of Power Electronics and Drive System (IJPEDS), vol. 10, no. 4, pp. 17241733, Dec 2019.

[20] Deepti Yadav, Arunima Verma, "Comparative Performance Analysis of PMSM Drive Using MPSO and ACO techniques," International Journal of Power Electronics and Drive System (IJPEDS), vol. 9, no. 4, pp. 1510-1522, Dec 2018.

[21] I.F Jr., et al., "A Brief Review of Nature-Inspired Algorithms for Optimization, "Elektrotehni ski Vestnik, English Edition, vol. 80, no. 3, pp. 1-7, 2013.

[22] R. Sharma, et al., "Performance evaluation of cuckoo search algorithm based FOPID controllers applied to a robotic manipulator with actuator", International Conference on Advances in Computer Engineering and Applications (ICACEA), IMS Engineering College, Ghaziabad, India, pp. 356-363, 2015. 
[23] R.Sharma, et al., "Performance Analysis of Two-Degree of Freedom Fractional Order PID Controllers for Robotic Manipulator with Payload," ISA Transactions, vol. 58, pp. 279-291, Sep 2015.

[24] X-S.Yang, "A New Metaheuristic Bat-Inspired Algorithm," in Nature Inspired Cooperative Strategies for Optimization (NICSO 2010), J. González, et al., Eds., ed: Springer Berlin Heidelberg, vol. 284, pp. 65-74, 2010.

[25] Reham H., et al., "Trajectory Tracking Control for Robot Manipulator using Fractional Order-Fuzzy-PID Controller, "International Journal of Computer Applications, vol. 134, no. 15, pp. 22-29, Jan 2016.

[26] X. S. Yang. "Bat algorithm for multi-objective optimization," Int. J. Bio-Inspired Computation, vol. 3.no. 5, pp. 267-274, 2011.

[27] K. Premkumar and B.V. Manikandan, "Bat algorithm optimized fuzzy PD based speed controller for brushless direct current motor," an International Journal of Engineering Science and Technology, vol. 19, pp. 818-840, 2016.

[28] D.K. Sambariya, et al., "Design of optimal input-output scaling factors based fuzzy PSS using bat algorithm," an International Journal of Engineering Science and Technology, vol. 19, pp. 991-1002, 2016.

[29] K. Singh, et al., "PID Tuning of Servo Motor using Bat Algorithm," Procedia Computer Science, vol. 60, pp. 1798-1808, 2015.

[30] M. Saraswathi, et al., "Optimal Path Planning of Mobile Robot Using Hybrid Cuckoo Search-Bat Algorithm," Procedia Computer Science, vol. 133, pp. 510-517, 2018.

[31] Jun-Yi Cao and Bing-Gang Cao, "Design of Fractional Order Controller Based on Particle Swarm Optimization," International Journal of Control, Automation, and Systems, vol. 4, no. 6, pp. 775-781, Dec 2006.

\section{BIOGRAPHIES OF AUTHORS}

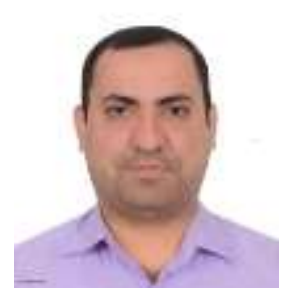

Mohammad. A. Faraj was born in Al-anbar, Iraq in 1982. He received the B.Sc. from the university technology, control and systems engineering department. Baghdad, Iraq, in 2004. And he received the M.Sc. degree from University of Technology, control and systems engineering department in 2008 , in mechatronics engineering specialization. In 2008 , he joined the department of electrical engineering at university of Al-Anbar, Ramadi, in Iraq, as an Asst. Lecturer. Currently he is a lecturer in the department of electrical engineering at university of university of $\mathrm{Al}$-Anbar, Ramadi, in Iraq. His research interest include adaptive control, control systems, robot manipulator, and mobile robot and optimization algorithms.

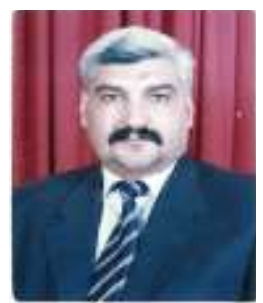

Abdulsalam Mohammed Abbood was born in babil, Iraq 1958. He received the B.S degree from the university of Sarajevo of Yugoslavia, in 1981 and M.S. degree from the university of Beograd of yogoslavia, in 1983. Currently he is a lecturer in the department of electrical engineering at university of university of Al-Anbar, Ramadi, in Iraq. He has published over 4 refereed journal and conference papers in the areas of electronic circuits. and electrical machine 